\title{
INFLUENCE OF SEVERAL SOIL PROPERTIES ON SOIL SURFACE REFLECTANCE
}

\author{
JeRZy CierniewsKi, KRZYSZtof Kú́NIEReK \\ Adam Mickiewicz University, Institute of Physical Geography and Environmental Planning, Poznań, Poland
}

Manuscript received January 15, 2010

Revised version March 5, 2010

CIERNIEWSKI J. \& KUŚNIEREK K., 2010. Influence of several size properties on soil surface reflectance. Quaestiones Geographicae 29(1), Adam Mickiewicz University Press, Poznań 2010, pp. 13-25 , Figs 6. Tabs 1. ISBN 978-83-2322136-4. ISSN 0137-477X. DOI: 10.2478/v10117-010-0002-9.

ABSTRACT. Several examples are provided here to quantify how the soil is influenced by the soil surface properties, i.e.: content and composition of organic matter, content of calcium carbonate, texture, moisture, as well as surface roughness. 28 soil samples were collected from the test area on a ground moraine, located north of Poznań. The soil samples were measured spectrally with an ASD FieldSpec 3 spectrophotometer in controlled laboratory conditions, in order to obtain a plot of the soil reflectance as a function of wavelength, from $400 \mathrm{~nm}$ to $2500 \mathrm{~nm}$. The soil samples were also analyzed in the laboratory to establish their selected properties. The research shows that all tested soil properties strongly influence the soil reflectance.

KEYWORDS: hyperspectral reflectance, soil, soil properties.

Jerzy Cierniewski, Krzysztof Kuśnierek, Institute of Physical Geography and Environmental Planning, Adam Mickiewicz University, Dzięgielowa 27, 61-680 Poznań, Poland, ciernje@amu.edu.pl, kus@amu.edu.pl

\section{Introduction}

Nearly the entire short-wave solar radiation in the optical domain (from $300 \mathrm{~nm}$ to $2500 \mathrm{~nm}$ ) incident on soil surface is either absorbed or reflected, and only a little of it is transmitted. The solid phase of the soil, mainly composed of different size opaque particles covered by organic matter and minerals (mostly clay, iron oxides and calcium carbonate), such as liquid and gas phases, decide the soil reflectance. These physicochemical properties, as well as the direction of the incident radiation and the direction along which the reflected radiation is viewed by a sen- sor, are considered to be the main influences on the reflectance of a soil sample with disturbed surface under laboratory conditions. Under field conditions the list of these properties must be completed with soil surface roughness that is usually higher and much more variable. Hence, the reflectance of a soil studied under these conditions may not be directly compared with the reflectance of the same soil analyzed under laboratory conditions.

The reflectance of soils, measured under laboratory conditions on samples with their disturbed surfaces, increases with a decrease of the soil particle size (Orlov, 1969; Bowers \& Smith, 
1972). Bowers \& Hanks (1965), testing the reflectance of soil materials of the texture from coarse clay to sand, found that the character of this relationship is exponential. Piech \& Walker (1974) confirmed the higher soil reflectance in the range of 500-900 nm with decreasing soil particle size ranging from $2 \mathrm{~mm}$ to less than $0.062 \mathrm{~mm}$. Studies of disturbed soils samples under laboratory conditions prove that the decrease of soil aggregate size results in an increase of the soil spectral reflectance. The smaller aggregates have a more spherical shape, but the larger ones have an irregular shape with a higher number of interaggregate spaces and cracks where the incident light is trapped (Mikhailova \& Orlov, 1986; Coulson \& Reynolds, 1971). The density of aggregate packing and surface roughness are the main physical features influencing the soil reflectance (Orlov, 1969; Orlov et al., 1976). The total reflectance from smaller aggregates varies widely, while the aggregates with a diameter in the 2-10 $\mathrm{mm}$ range have a fairly constant reflectance (Orlov, 1969; Curran et al., 1990). Irregularities of the soil surface, caused only by the soil texture for laboratory soil samples with disturbed natural surfaces, and mainly by aggregates and micro-relief configuration for surfaces in natural field conditions, cause areas of shadow, where the solar beams do not reach the surface directly. The energy of waves leaving the area is many orders-of-magnitude smaller than the energy reflected from sunlit soil fragments. Opaque soil particles and aggregates with dominant diffuse features, usually seem to be the brightest from the direction which gives the lowest proportion of shaded fragments These soil surfaces in both laboratory and field conditions usually display a clear backscattering character, with a reflectance peak towards the light source or the Sun position ('hot spot' direction), and decreasing reflectance in the direction away from the peak (Cierniewski, 1987).

The higher the organic matter content (OM), the lower the reflectance of soils. A small increase of the OM content in soil samples with the OM amount lower than $1 \%$, results in a significant decrease of their reflectance. For the OM content lower than $1.5-2 \%$, this relation is less close, because it is weakened by the influence of mineralogical composition variety of soil particles not covered by OM. Mikhaylova \& Orlov (1986), investigating the relation between the OM content and the soil reflectance in the visible and the near infrared, reported that it is closest in the wavelength range of 600-700 nm. Dalal \& Henry (1986), studying this relation in a wider spectrum, found that the OM content is highest correlated with the soil reflectance at the wavelength of $1,744 \mathrm{~nm}$, $1,870 \mathrm{~nm}$ and $2,052 \mathrm{~nm}$. Not only the OM content, but also the proportion of main organic carbon fractions, the humic and fulvic acids, decides the reflectance of soil (Białousz, 1979; Mikhaylova \& Orlov 1986). The dry concentrate of the humic acids and fulvic ones reflects the visible radiation on a level of about $2 \%$ and $7 \%$, respectively (Obukhov \& Orlov 1964).

The higher the calcium carbonate content of soil samples with their natural surfaces disturbed under laboratory conditions, the higher their reflectance is. Lagacherie et al. (2008) found that this substance most strongly absorbs the electromagnetic waves of the 2,208 $\mathrm{nm}$ and 2,341 nm wavelength. The $\mathrm{CaCO}_{3}$ affects the soil reflectance under field conditions weaker than the OM. Białousz (1978) mentioned that the relation becomes directly proportional only if the $\mathrm{CaCO}_{3}$ content is higher than $20 \%$. For a lower content, the relation is inversely proportional and has an indirect character. The substance, since it is conductive to forming of soil aggregates, causes a higher roughness and therefore decreases the soil reflectance.

The mineral and organic fractions of soil materials, mentioned above, absorb shorter wavelengths more than the longer ones. Hence a soil reflectance spectrum has a shape of a clearly raising curve with increase in the wavelength. In the middle infrared, i.e., from 1,300 $\mathrm{nm}$ to $2,500 \mathrm{~nm}$, the soil reflectance stabilizes itself or decreases a little with the wavelength. In the range of around $1,450 \mathrm{~nm}$ and 1,950 $\mathrm{nm}$, where the radiation is strongly absorbed by water molecules, the two deep minima are usually observed in soil spectra, especially collected in the field (Stoner \& Baumgardner, 1981).

Soil surface moisture is a factor which changes the spectral levels most dynamically. General$l y$, an increase in soil moisture causes a decrease in level of the spectra. This decrease is clearer for light color soils, with a low content of organic 
matter, than for dark ones (Mikhaylova \& Orlov, 1986). Along with the increase of soil moisture from oven-dry soil to the hygroscopic capacity, the spectra levels do not change (Tolchelnikov, 1974; Cierniewski, 1985) or it drops a little (Vinogradov, 1983). With a further increase in water content to the field capacity, the spectra levels decrease sharply, in proportion to the increase in the water content in the soil (Bowers \& Smith, 1972; Tolchelnikov, 1974; Vinogradov, 1983). A further increase in soil water content to full saturation does not bring about any change in spectra levels (Tolchelnikov, 1974; Vinogradov, 1983) or causes their slight increase (Białousz et al., 1978; Cierniewski, 1985, 1993; Music \& Pelletier, 1986). The changes in the soil reflectance curve over these three moisture ranges are explained by the dissimilarity of the forms of water. In the first range, from zero moisture to the hygroscopic capacity, there is only chemically bound water, water vapor and hygroscopic water. In the second one, up to the field capacity, water surrounds soil particles in the form of a film or it fills capillaries and small pores. In the third moisture range it has the form of gravimetric water. The drop in soil reflectance curve with the increase in soil moisture is caused by the increasing proportion of liquid water to air, which is different under refraction and light conductivity (Reginato et al., 1977).

Modern spectroradiometers allow us to precisely measure soil reflectance spectra in natural conditions, where soil surfaces are illuminated by direct and diffuse solar radiation, as well as under laboratory conditions, where the surfaces are usually illuminated by one artificial light source. Currently, the device most commonly used for it all over the world is the ASD FieldSpec3 spectroradiometer, regarded as a standard tool by the International Union of Soil Science (Viscarra-Rossel, 2008). This tool enables us to give the abovementioned knowledge a more quantitative character. Having a representative library of soil spectral curves along with analytical results, it is possible to develop regression models for the estimation of the content of soil constituents, i.e.: the soil organic carbon, iron oxides, calcium carbonate and soil textural composition.
The aim of this paper is to show quantitatively how strongly soil surfaces properties can modify the soil reflectance in the optical domain. Examples related to soils developed from sandy and loamy ground moraine material, which dominate in Poland, were used here. This relation was tested for the majority of soil properties that significantly influence their reflectance features in the optical domain, i.e.: content and composition of soil organic matter, content of calcium carbonate, texture, moisture, as well as soil surface roughness.

\section{Methods}

\section{Test area}

The research was conducted in a test area located north of Poznań $\left(52.493^{\circ} \mathrm{N} ; 16.928^{\circ} \mathrm{E}\right)$, within a ground moraine, characterized by a large altitude variations to provide soil samples with a sufficient differences in organic matter content, as well as soil texture and calcium carbonate content.

During the field campaign, carried out during October 2008, 28 soil samples from depth of $0-20 \mathrm{~cm}$ were collected. Their location in the background of the hypsometric map is presented on Fig. 1.

\section{Physical and chemical analyses}

All the collected samples were examined in the laboratory, to test their physical and chemical properties that significantly influence their spectral reflectance. Their textural composition was examined using the hydrometer method. Soil organic carbon (SOC) content was analyzed by Walkley Black's method, and calcium carbonate equivalent was measured by Piper's method. These properties are completed by the color of the air dry soil samples, determined using Munsell Standard Soil Color Charts. Additionally, for two selected samples, the ratio of soil organic matter fractions was determined using an alkali extraction method, recommended by the International Humic Substances Society (Sparks et al. 1996). 


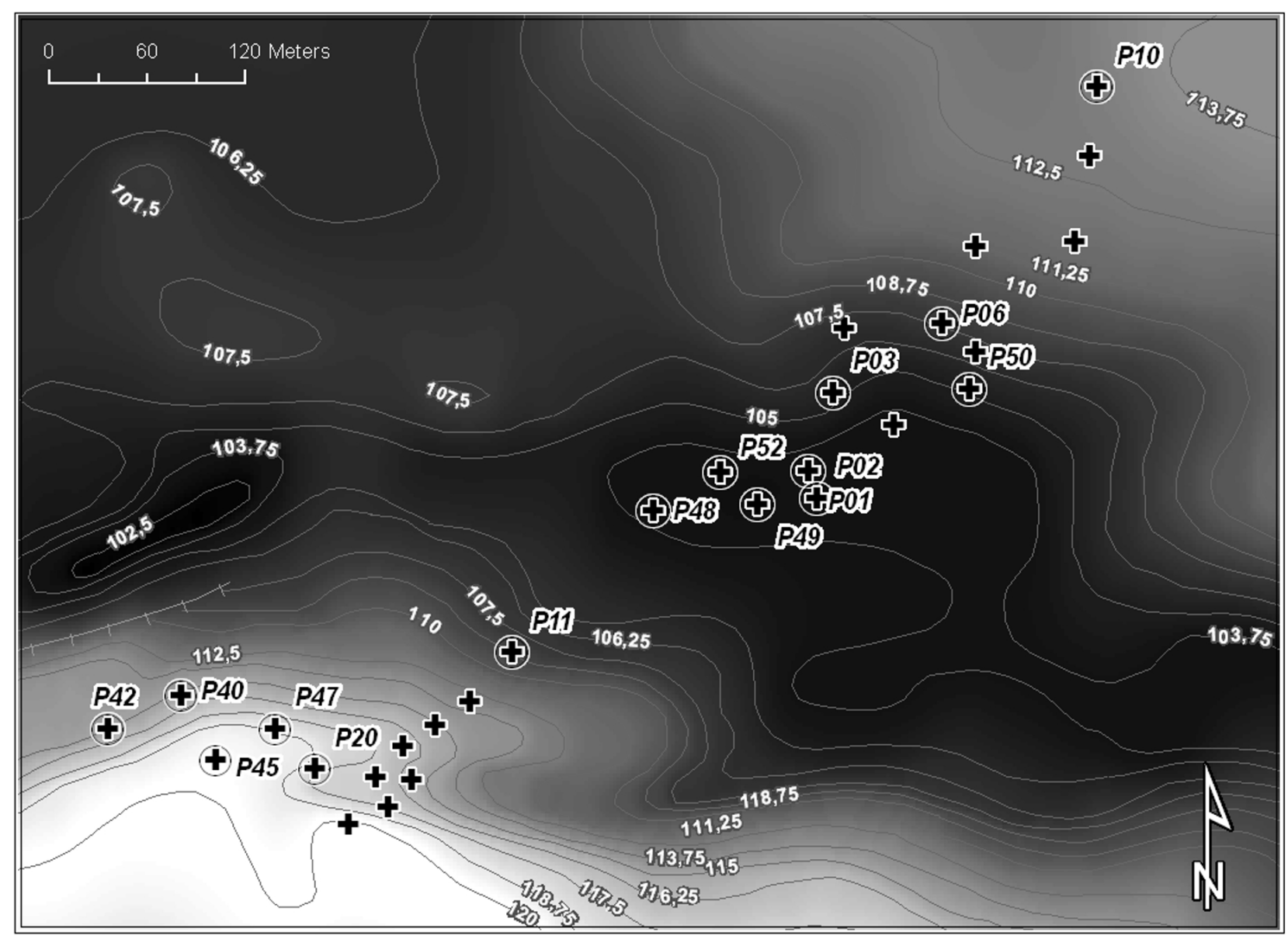

Fig. 1. Location of all the collected samples (crosses) and those among them, selected for detailed analyses (crosses surrounded by circles).

\section{Spectral measurements}

The soil material measured spectrally was air-dried, sieved through a $2 \mathrm{~mm}$ sieve and poured into black painted Petri dishes of $8 \mathrm{~cm}$ in diameter and $0.5 \mathrm{~cm}$ in height and then scraped with a ruler to avoid compressing it. The radiation reflected from the soil samples prepared in this way was measured using an ASD FieldSpec Pro 3 spectroradiometer in ten repetitions per each sample. The spectroradiometer allows fast spectral measurements in the optical region of $350-2,500 \mathrm{~nm}$ with spectral resolution of $3 \mathrm{~nm}$ and $10 \mathrm{~nm}$ under and over 1,000 nm, respectively. Thus, the device provides the radiation data in 366 channels. For the measurement carried out under laboratory conditions, the instrument was equipped with a ContactProbe with own inner light source. A direct contact between this probe and a sample eliminates the atmosphere impact on the reflectance results of the examined samples. Their reflectance is expressed as the ratio of the radiation reflected from a soil sample to the radiation reflected from the white reference panel, the Spectralon of Labsphere, both measured and illuminated in the same conditions. The laboratory spectral measurements were conducted for all 28 of collected samples.

To obtain an example which demonstrates the influence of soil roughness on the soil reflectance, one from the examined samples was also tested spectrally under field conditions. The field experiment was conducted on $29^{\text {th }}$ June 2009 under clear sky conditions at the solar zenith angle of about $40^{\circ}$. The spectroradiometer was equipped with a hand probe sensor with a $25^{\circ}$ field-of-view. The sensor, looking at the nadir from the height of $1 \mathrm{~m}$, collected the soil radiation, reflected from its soil circular footprint of $44 \mathrm{~cm}$ diameter. 


\section{Spectral analysis}

The results of the physical and chemical laboratory analyses, as well as the spectral radiation measurements related to all the collected samples, were compiled into specific data sets.

To determine the influence of the content of: the organic carbon, clay fraction and calcium carbonate on the shape and the level of the soil reflectance spectra, three soil samples for each of the soil constituent separately were selected from all the collected data. These three chosen samples were similar in all the numbers characterizing their examined properties except one being analyzed in a given set as influencing the soil reflectance. For example, analyzing the influence of the soil organic carbon content, three samples with similar content of the clay fraction and calcium carbonate, but essentially different in the organic carbon content were selected. The influence of the organic carbon content on the soil reflectance was tested in two sets: one that includes soil samples with high organic carbon content and high humic to fulvic organic matter fraction ratio $\left(\mathrm{OM}_{\mathrm{H} / \mathrm{F}}\right)$; another that consists of samples with a small amount of organic carbon and domination of the fulvic fraction. The analysis carried out on these two sets of the samples enables us to notice an influence of the soil organic matter composition, too.

To analyze the influence of soil water content on the soil reflectance, two samples that are different in clay fraction content, retaining different amount of water, were selected.

Three different water contents of both samples were analyzed. The soil material of these samples was poured into a $50 \mathrm{~cm}^{3}$ cylinder with a diameter of $5.5 \mathrm{~cm}$ and a height of $3 \mathrm{~cm}$, scraped with a ruler and then placed on a dish with water, where it was completely saturated. The first spectral measurements were taken using the ContactProbe when the samples reached this moisture state, corresponding to the maximum water capacity. The next measurements were carried out after the samples were dried in a drier for three hours, what approximated the field water capacity. The probe measured the soil reflectance from the inside surface of a sample after cutting it into two pieces. The examined samples were consolidated and weighed to asses their water content. The final spectral measurements were taken for the samples at the minimum water capacity, after they were dried in a drier in $105^{\circ} \mathrm{C}$ for $24 \mathrm{~h}$. To precisely asses the water content in a given sample, the sample was weighed twice, before and after the spectral measurement, and results of the weighing were used as their average value.

\section{Results and discussion}

The soils of the test area were classified as: Sapric Calcic Histosols Drainic, Cutanic Calcic Luvisols and Cutanic Endogleyic Luvisols, according the WRB2006 (Bednarek et al., 2009). The table 1 shows the soil properties of the 15 samples selected for a detailed analysis to determine the content and composition of soil organic carbon the content of mechanical fraction and calcium carbonate, soil water content and soil surface roughness on the soil reflectance in the optical domain. These samples were chosen from all 28 collected samples.

The places from which the samples were collected are situated between $102 \mathrm{~m}$ to 119 $\mathrm{m}$ above sea level. The collected soil samples represent a wide range of soil organic content, from about $9 \%$ in the lower part of the tested area (P49) to about $1 \%$ in its upper part (P06) (Table 1, Fig. 1). The soil samples collected there also differ in the composition of the soil organic matter, expressed by the $\mathrm{OM}_{\mathrm{H} / \mathrm{F}}$. The soil sample P49, collected from places located lower than $106 \mathrm{~m}$ above see level, is characterized by a high $\mathrm{OM}_{\mathrm{H} / \mathrm{F}}$ of 3:1. The soil sample P06, with a lower SOC content, is described by the $\mathrm{OM}_{\mathrm{H} / \mathrm{F}}$ of 1:3. The variation in the calcium carbonate content is similar to the organic carbon content. The highest content of the $\mathrm{CaCO}_{3}$ was established in the soil samples collected from the lower parts of the area. For the soils of the area located higher, no $\mathrm{CaCO}_{3}$ content was found. The collected samples provided a wide variation of texture: from soils rich in sand fraction, (P02, P48), through soils with a similar content of silt and clay (P45), to soils of a high content of clay fraction (P40, P47). Two soil samples (P20, P47) were used to find the relation between the soil water content and the soil reflectance. All the selected samples 
TAble 1. Properties of SOIL SAMPles SELECted For the Detailed ANALysis

\begin{tabular}{|c|c|c|c|c|c|c|c|c|c|c|c|c|}
\hline \multirow{2}{*}{ Label } & \multirow{2}{*}{$\begin{array}{c}\text { Soil } \\
\text { unit } \\
\text { (WRB) }\end{array}$} & \multicolumn{3}{|c|}{$\begin{array}{c}\text { Mechanical fraction } \\
\text { content }[\%]\end{array}$} & \multirow{2}{*}{$\begin{array}{l}\text { SOC } \\
{[\%]}\end{array}$} & \multirow{2}{*}{$\mathrm{OM}_{\mathrm{H} / \mathrm{F}}$} & \multirow{2}{*}{$\begin{array}{c}\mathrm{CaCO}_{3} \\
{[\%]}\end{array}$} & \multirow{2}{*}{$\begin{array}{l}\text { Wd } \\
{[\%]}\end{array}$} & \multirow{2}{*}{$\begin{array}{l}\text { Wi } \\
{[\%]}\end{array}$} & \multirow{2}{*}{$\begin{array}{l}\mathrm{Wm} \\
{[\%]}\end{array}$} & \multirow{2}{*}{$\begin{array}{l}\text { Dry Mun- } \\
\text { sell } \\
\text { soil colour }\end{array}$} & \multirow{2}{*}{$\begin{array}{c}\mathrm{S} \\
{[\%]}\end{array}$} \\
\hline & & sand & silt & clay & & & & & & & & \\
\hline P10 & CCL & 74 & 13 & 13 & 0.82 & NM & NM & NM & NM & NM & $2.5 Y R 5 / 3$ & 3 \\
\hline P06 & CEL & 69 & 18 & 13 & 1.06 & $1 / 3$ & NM & NM & NM & NM & $2.5 \mathrm{YR} 5 / 3$ & 7 \\
\hline P11 & CCL & 70 & 17 & 13 & 1.31 & NM & NM & NM & NM & NM & $2.5 \mathrm{YR} 4 / 3$ & 6 \\
\hline P02 & SCHD & 78 & 19 & 3 & 4.70 & NM & 5.99 & NM & NM & NM & $2.5 \mathrm{YR} 3 / 3$ & 1 \\
\hline P49 & SCHD & 76 & 22 & 2 & 5.96 & $3 / 1$ & 7.64 & NM & NM & NM & $2.5 \mathrm{YR} 3 / 2$ & 0.5 \\
\hline P03 & SCHD & 72 & 24 & 4 & 6.89 & NM & 9.41 & NM & NM & NM & $2.5 \mathrm{YR} 3 / 2$ & 5 \\
\hline P40 & CCL & 35 & 28 & 37 & 2.18 & NM & NM & NM & NM & NM & $2.5 Y R 5 / 3$ & 12 \\
\hline P45 & CCL & 43 & 27 & 30 & 2.09 & NM & NM & NM & NM & NM & $2.5 \mathrm{YR} 5 / 3$ & 2 \\
\hline $\mathrm{P} 42$ & CCL & 54 & 22 & 24 & 2.23 & NM & NM & NM & NM & NM & $2.5 \mathrm{YR} 5 / 3$ & 7 \\
\hline P48 & SCHD & 75 & 22 & 3 & 9.04 & NM & 15.56 & NM & NM & NM & $2.5 \mathrm{YR} 3 / 2$ & 2 \\
\hline P52 & SCHD & 79 & 18 & 3 & 9.04 & NM & 11.21 & NM & NM & NM & $2.5 \mathrm{YR} 3 / 2$ & 1 \\
\hline P01 & SCHD & 78 & 19 & 3 & 9.06 & NM & 7.05 & NM & NM & NM & $2.5 \mathrm{YR} 3 / 2$ & 1 \\
\hline P47 & CCL & 33 & 27 & 40 & 1.98 & NM & NM & 0 & 30 & 57 & 2.5YR5/4 & 7 \\
\hline P20 & CCL & 53 & 24 & 23 & 1.13 & NM & NM & 0 & 28 & 45 & $2.5 \mathrm{YR} 6 / 4$ & 6.5 \\
\hline P50 & SCHD & 76 & 22 & 2 & 2.40 & NM & 0.44 & NM & NM & NM & $2.5 \mathrm{YR} 4 / 2$ & 4 \\
\hline
\end{tabular}

Label - label of a soil sample

sand - sand (2-0.05 $\mathrm{mm})$ fraction content in \%

silt - silt $(0.05-0.002 \mathrm{~mm})$ fraction content in \%

clay - clay $(<0.002 \mathrm{~mm})$ fraction content in $\%$

SOC - content of soil organic carbon in $\%$

$\mathrm{OM}_{\mathrm{H} / \mathrm{F}}$ - humic to fulvic organic mater fraction ratio

$\mathrm{CaCO}_{3}$ - content of calcium carbonate in \%

S - slope inclination in \%

Dry Munsell soil colour - soil colour refered as Munsell's hue, value and chroma

are characterized by the same Munsell color hue of 2.5YR.

The soil reflectance spectra presented below are a mean of 10 measurements taken from a particular soil sample. These spectral curves in all analyzed examples are supported by 'ratio spectra', i.e. the spectral curves transformed by dividing a given spectral curve by the curve of the highest reflectance in a particular set. These transformed spectra express a quantitative influence of a specific soil property on soil reflectance and define a spectral range with the strongest influence of tested soil property on soil reflectance. The left $Y$ axis of each chart relates to the reflectance spectra (solid lines), while the right one refers to the 'ratio spectra' (dashed lines).

\section{The content and the composition of the soil organic carbon}

The influence of the SOC content on the soil reflectance is analyzed here using two sets of spectral data. The first set (Fig. 2a) is comprised of soil samples with low content of SOC and higher level of fulvic acid fraction than the hu- 
(a)

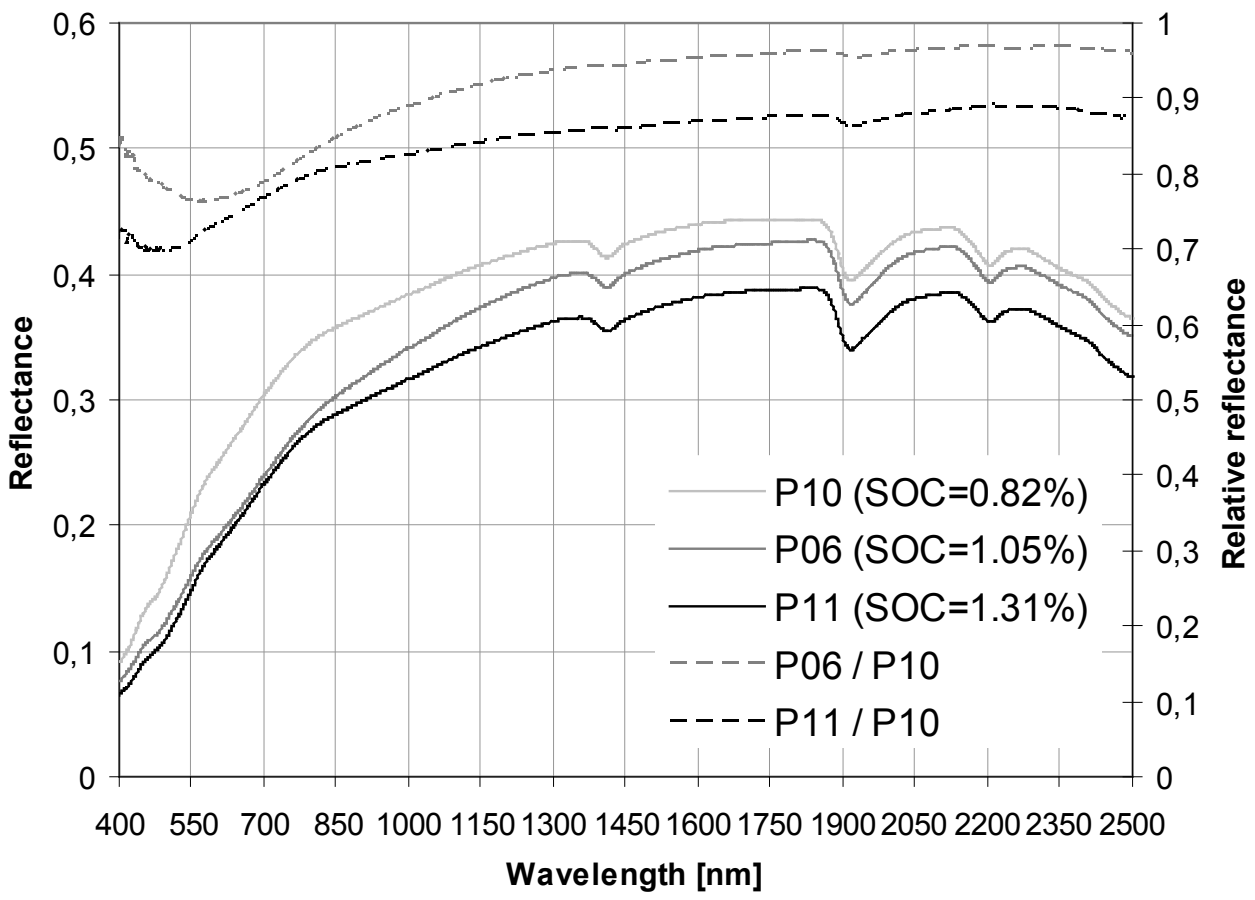

(b)

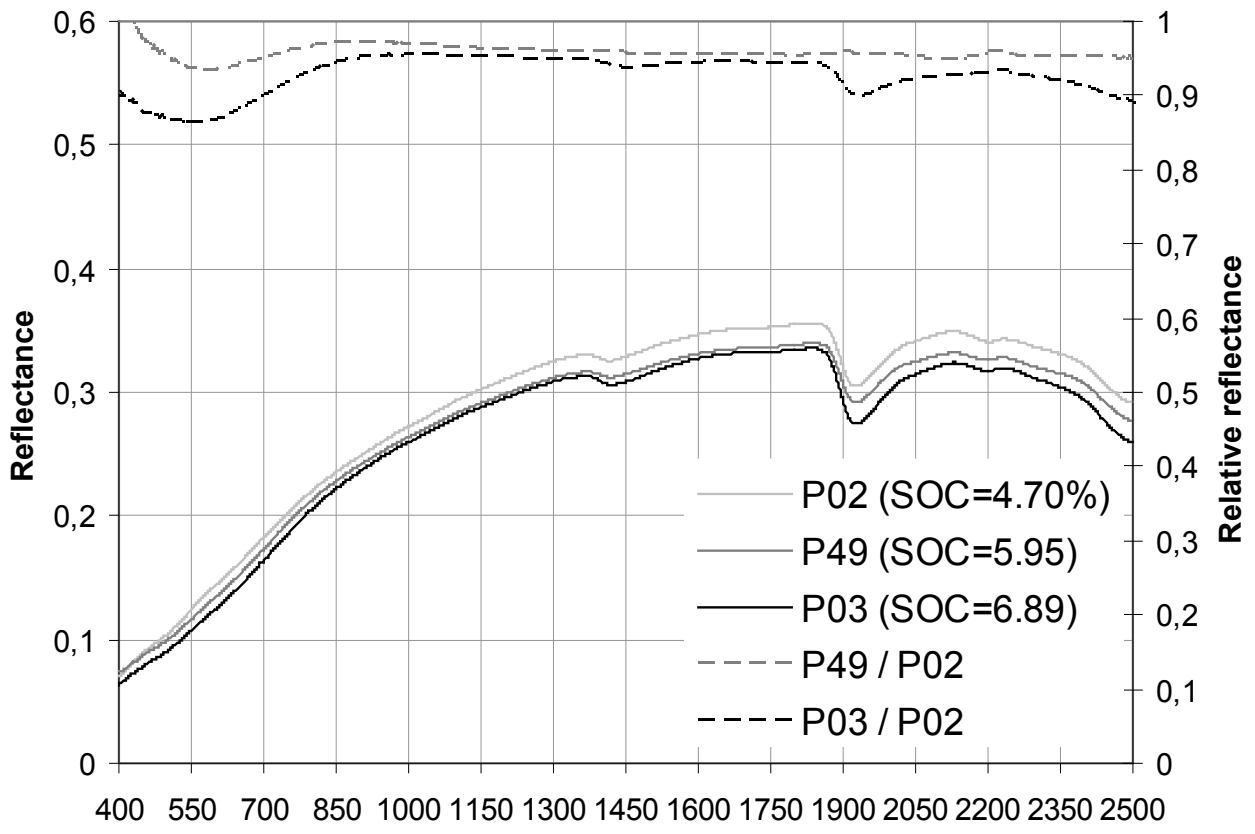

Wavelength [nm]

Fig. 2. Examples of the spectral reflectance curves of soil samples similar in all examined properties except for the SOC content (solid lines: P10, P06, P11 and P02, P49, P03) and the transformed curves P06, P11 and P49, P03 as the effect of dividing them by the curves of the highest reflectance in each set: P10 and P02, respectively (dashed lines: P06/P10, P11/P10 and P49/P02, P3/P2). (a) and (b) relates to a low and a high SOC content, respectively. 
mic one and their reflectance exceeds a level of 0.4 in the short infrared region (SWIR) between $1,300 \mathrm{~nm}$ and 2,500 $\mathrm{nm}$. The second set (Fig. 2b) consists of soil samples with a high SOC content and a higher amount of the humic acid fraction than the fulvic one. The soil reflectance for this data set is higher than 0.3 in the SWIR. The influence of the SOC content for both data sets is the most clear in the spectral region from $400 \mathrm{~nm}$ to $700 \mathrm{~nm}$. This wavelength region is similar to that determined by Mikhaylova \& Orlov (1986). For the first data set, the increase of the SOC of about $0.5 \%$ results in the average drop of soil reflectance of $25 \%$ in the analyzed spectral region (Fig. 2a).

For the second set, the increase of SOC content of about $1 \%$, generates a decrease of soil reflectance of about $5 \%$ (Fig. $2 b$ ). Thus, a two times higher content of the SOC in soils of a high humic to fulvic organic matter fraction ratio $\left(\mathrm{OM}_{\mathrm{H} / \mathrm{F}}\right)$ causes five times greater decrease of the soil reflectance in relation to the soils of a low $\mathrm{OM}_{\mathrm{H} / \mathrm{F}}$.

These two different quantitative relationships between the SOC content to the soil reflectance clearly reveal the influence of organic matter composition on soil reflectance, expressed by the $\mathrm{OM}_{\mathrm{H} / \mathrm{F}}$. In the analyzed data, a specific spectral pattern is observed in the spectral region between $400 \mathrm{~nm}$ and $700 \mathrm{~nm}$. If the $\mathrm{OM}_{\mathrm{H} / \mathrm{F}}$ is low the soil spectral curves are concave, while if the $\mathrm{OM}_{\mathrm{H} / \mathrm{F}}$ is high they are convex.

\section{The calcium carbonate content}

The higher the $\mathrm{CaCO}_{3}$ content, the higher the soil reflectance. A similar rise of the reflectance level between the presented spectra (P48, P52, P01), caused by almost the same increase of their $\mathrm{CaCO}_{3}$ content, suggests that this relation is almost directly proportional. The soil reflectance decreases by $7 \%$ in the spectral region over 1000 nm with a decrease of the $\mathrm{CaCO}_{3}$ content by about $4 \%$ (Fig. 3). The 'ratio spectra', presented in the example below, show a weak influence of the $\mathrm{CaCO}_{3}$ on the soil reflectance in the region between $550 \mathrm{~nm}$ and $700 \mathrm{~nm}$.

The three selected reflectance spectra (P48, P52, P01) reveal a minor absorption band situated near the wavelength around $2200 \mathrm{~nm}$, such as earlier found by Lagacherie et al. (2008).

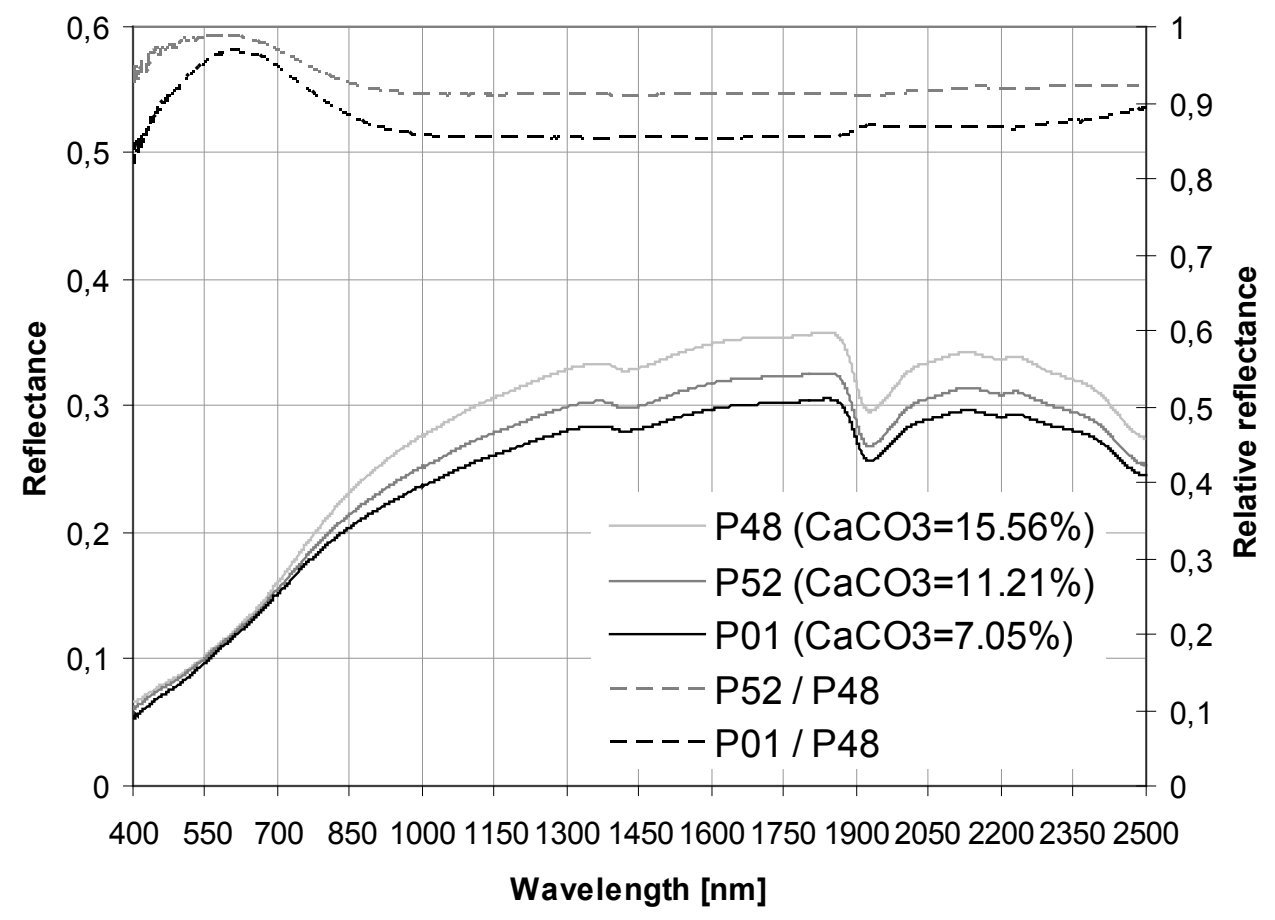

Fig. 3. The spectral reflectance curves of soil samples similar in all properties except the calcium carbonate $\left(\mathrm{CaCO}_{3}\right)$ content (solid lines: P48, P52, P01) and the transformed "ratio spectra" (dashed lines: P52/P48, P01/P48) as the effect of dividing of spectra P52 and P48 to a spectra of the highest reflectance, P48. 


\section{The soil clay fraction content}

The influence of the clay fraction on soil reflectance is the most evident in the spectral region from 500 to $700 \mathrm{~nm}$ (Fig. 4). The reduction of clay fraction content by $13 \%$, from $37 \%$ to $24 \%$ between samples $\mathrm{P} 40$ and P42, respectively, results in the average drop of spectral reflectance of about $10 \%$ in the analyzed region. The examined relationship is less strict in water absorption bands at $1450 \mathrm{~nm}$ and $1950 \mathrm{~nm}$ and the spectral range beyond $2000 \mathrm{~nm}$.

The example provided here confirms the findings of Piech \& Walker (1974), who stated that a decreasing soil particle size in the range of 500-900 nm causes higher soil reflectance for disturbed soils samples under laboratory conditions. A similar relationship between soil particle size and the soil reflectance was also reported by Clark (1999), investigating the reflectance of rocks and minerals in the entire optical domain.
The soil sample P47 of a clay fraction content of $40 \%$ retains a maximum of $50 \%$ of water, while the sample P20, containing $23 \%$ of the clay fraction, retains a maximum of $45 \%$ of water.

The examples show that soil surface water content strongly influence the soil reflectance. It is clear that the entire spectrum decreases with the increase of the soil water content. Obviously, this relationship is the most noticeable in the spectral regions of 1,450 and 1,950 nm (Stoner \& Baumgardner, 1981). The complete elimination of water content from both fully saturated samples to their dry state causes an about $80 \%$ and $90 \%$ increase of their soil reflectance in the spectral region of $1450 \mathrm{~nm}$ and $1950 \mathrm{~nm}$, respectively. Excluding these spectral regions, this increase does not exceed $50 \%$ and $80 \%$ in the near infrared and short infrared spectral regions, respectively. Significant differences in the soil reflectance occur also at the edges of the analyzed spectral range at $400 \mathrm{~nm}$ and $2,500 \mathrm{~nm}$, what is probably an effect of the ab-

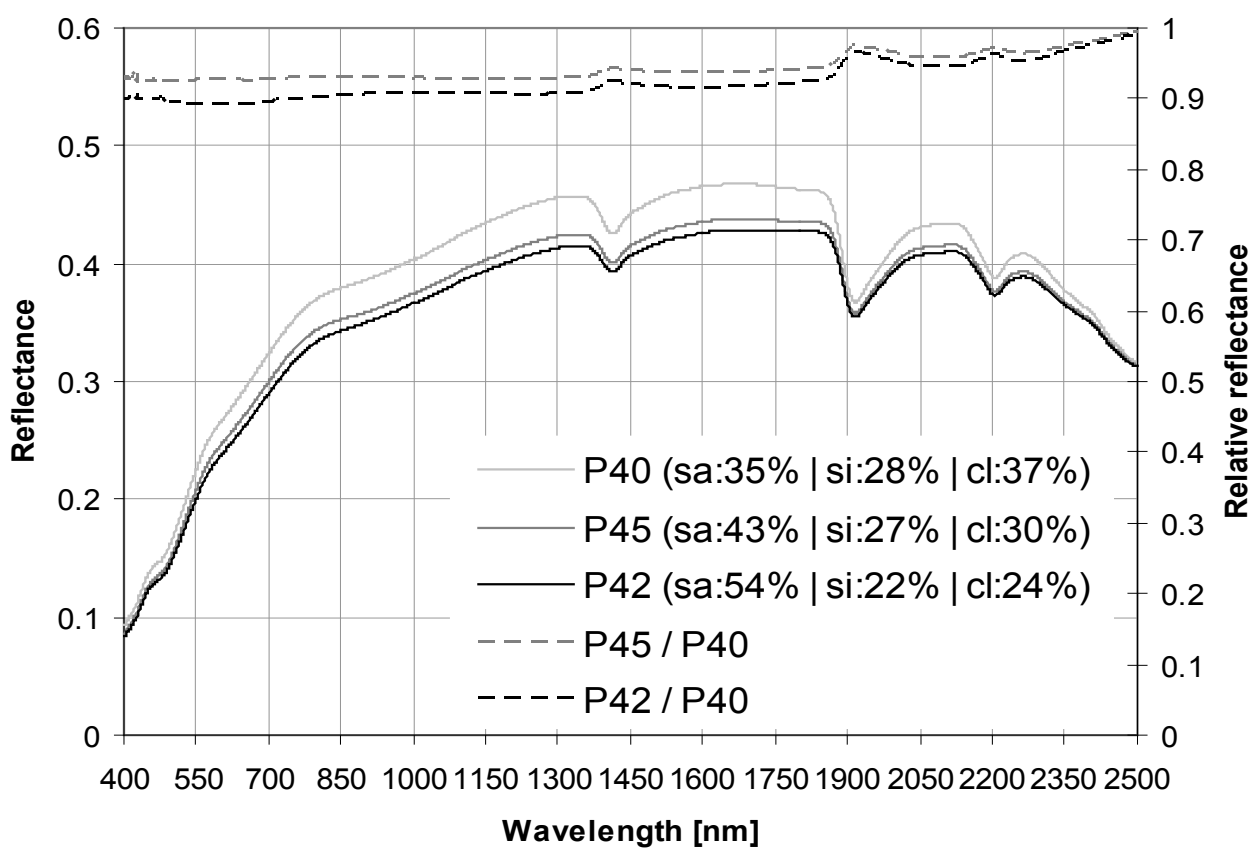

Fig. 4. The spectral reflectance curves of soil samples similar in all properties except clay fraction content (solid lines: P40, P45, P42) and transformed "ratio spectra" (dashed lines: P45/P40, P42/P40) as a result of dividing the P45 and P42 spectra by the spectra of the highest reflectance, $\mathrm{P} 40$.

\section{The soil water content}

The maximum water capacity retained by the soil depends on clay fraction content. This dependency is presented in the examples below (Fig. 5). sorption bands located outside the analyzed spectrum. The assessment of soil water content with the hyperspectral reflectance measurements in the discussed absorption bands is possible only under controlled laboratory conditions. Under field 
(a)

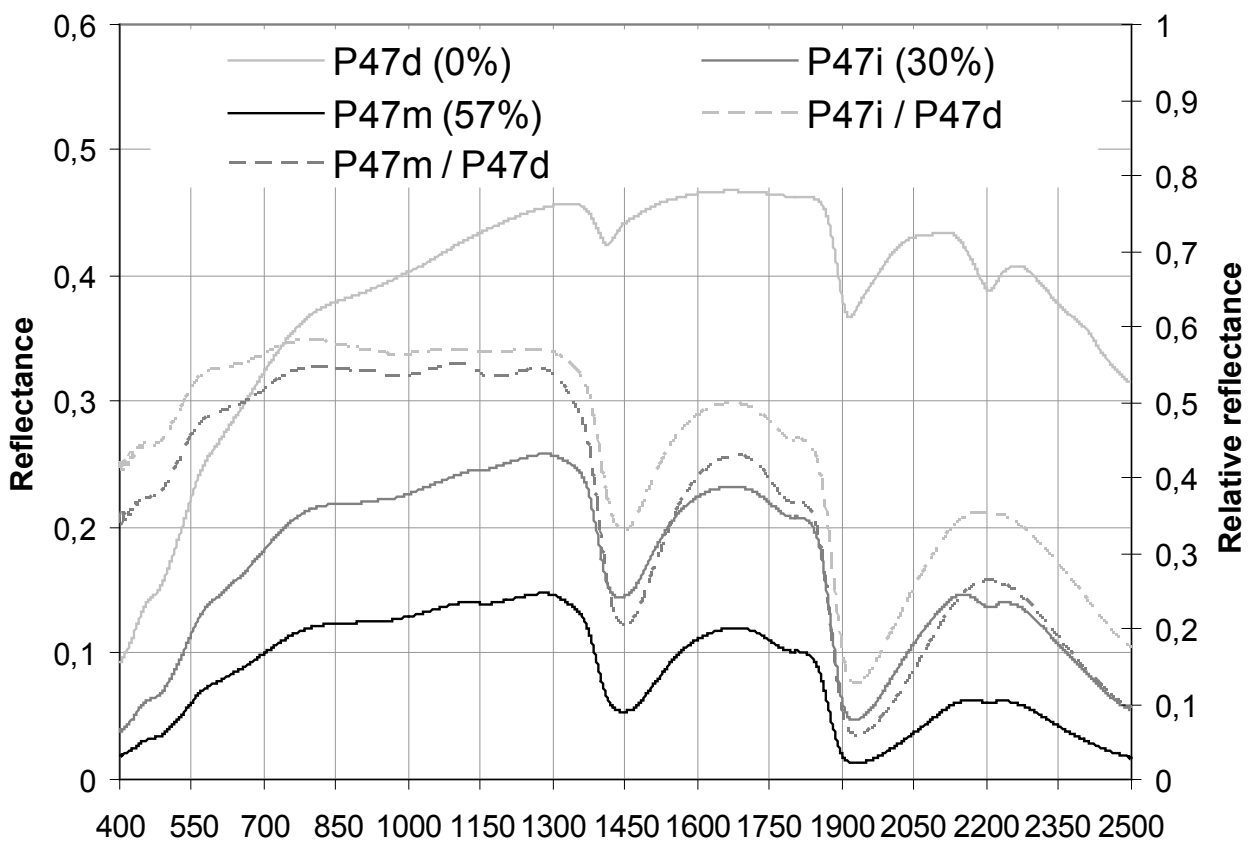

Wavelength [nm]

(b)

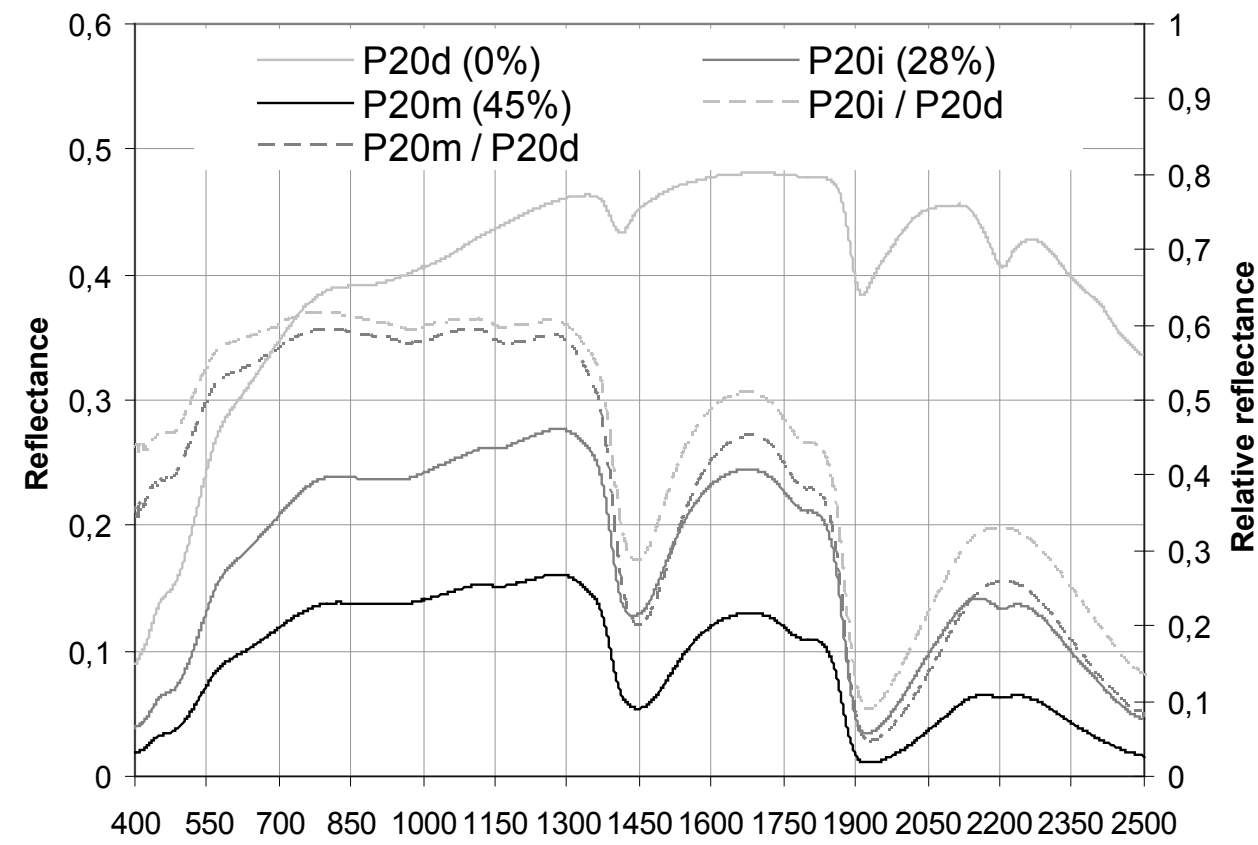

Wavelength [nm]

Fig. 5. Spectral reflectance curves of the soil sample of a higher clay fraction content, P47 (a), and lower clay fraction content, P20 (b). The symbols ' $d$ ', ' $i$ ' and ' $m$ ' stand for dried soil sample, intermediate water content state and saturated state, respectively. The soil reflectance spectra are presented in solid lines, and the transformed "ratio spectra", as a result of dividing spectra of P20i and P20m by P20d, in dashed lines. 
conditions, the water vapor in the atmosphere affects the soil reflectance in the both bands, so they must be excluded from the analysis.

\section{The soil roughness}

The example below (Fig. 6) does not explain an influence of the soil roughness on soil reflectance but only shows what spectral differences occur between the reflectance of disturbed soil surface measured under laboratory conditions (P50FL) and the reflectance of the natural soil surface measured under field conditions (P50RF). The presence of water vapor in the atmosphere affects the soil spectra collected in field measurement (P50RF) in bands centred in $1450 \mathrm{~nm}$ and $1950 \mathrm{~nm}$, as well as in a band centred outside the analyzed spectrum, near $2,500 \mathrm{~nm}$. It results in a high noise in those reflectance spectra regions from which the reflectance data was removed.

The overall reflectance of the naturally rough surface (P50RF) is clearly lower than the reflectance of the disturbed flat one (P50FL). The soil reflectance measured under field conditions in comparison to the reflectance collected under laboratory conditions is lower by about $20 \%$ in the range from $400 \mathrm{~nm}$ to $700 \mathrm{~nm}$.

\section{Conclusions}

The presented soil spectra show quantitatively how strongly the soil reflectance is modified by the content of the organic carbon, calcium carbonate, clay and water, as well as the roughness in the optical domain. The relationship of the soil reflectance and a given soil property was tested in sets of soil samples similar in all examined properties except the analyzed one. The analyses were supported by transformed 'ratio spectra', the result of dividing a reflectance spectra by the spectra of the highest reflectance in a given set. The 'ratio spectra' provided the information on the spectral region where the influence of a given soil constituent is the strongest.

The soil organic matter content affects soil reflectance mostly in the visible region from 400 $\mathrm{nm}$ to $700 \mathrm{~nm}$. The two times higher content of the soil organic carbon in soils of a high humic to fulvic organic matter fraction ratio $\left(\mathrm{OM}_{\mathrm{H} / \mathrm{F}}\right)$ causes five times greater decrease of the soil reflectance in relation to the soils of a low $\mathrm{OM}_{\mathrm{H} / \mathrm{F}}$. The soil reflectance decreases by $7 \%$ in the spectral region over $1,000 \mathrm{~nm}$ with a decrease of the $\mathrm{CaCO}_{3}$ content by about $4 \%$. The influence of clay fraction content on soil reflectance is most noticeable in the spectral region from 500 to

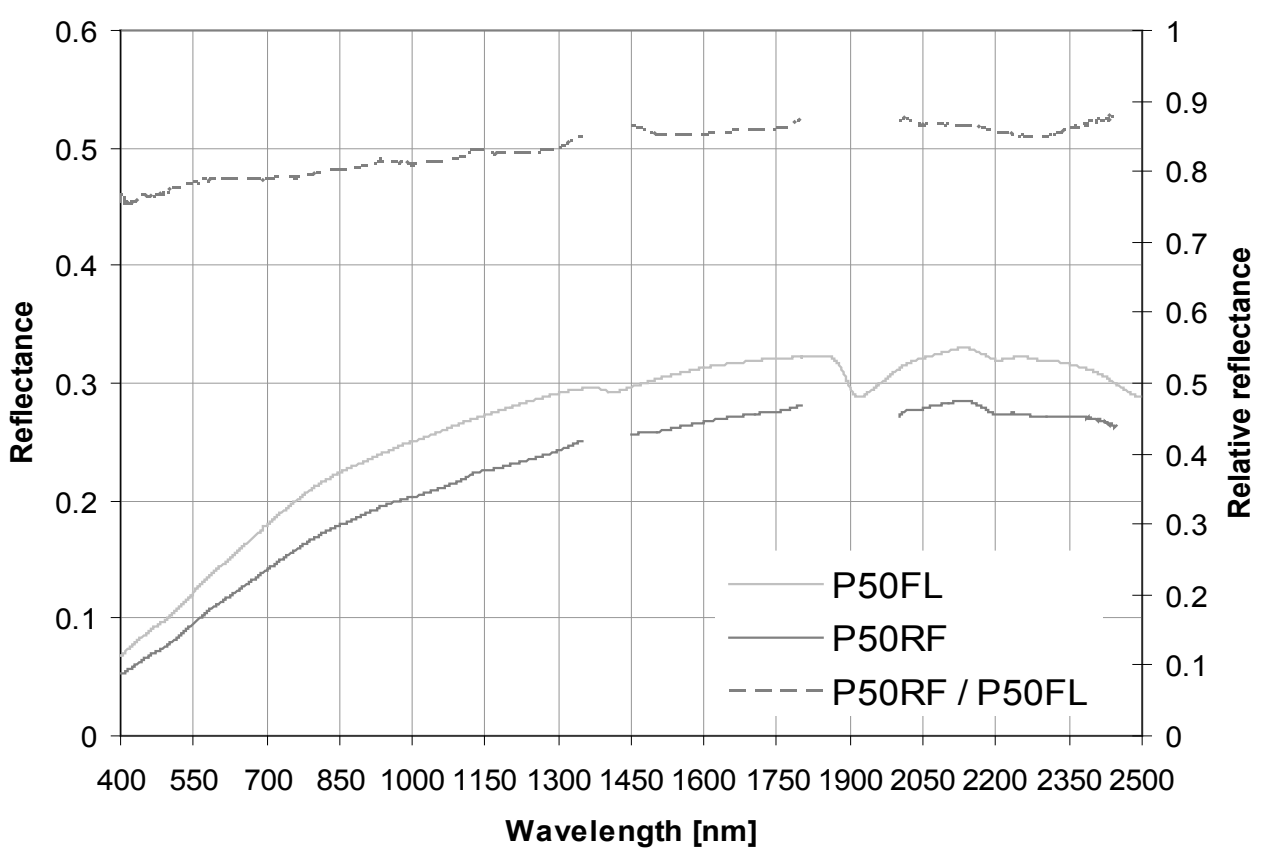

Fig. 6. Spectral reflectance curves (solid lines) of the flat soil surface measured spectrally under laboratory conditions (P50FL) and the rough soil surface measured under field conditions (P50RF). The dashed line shows the transformed "ratio spectrum" as a result of dividing the spectrum P50RF by P50FL . 
$700 \mathrm{~nm}$. The reduction of clay fraction content of $13 \%$ results in the drop of spectral reflectance of $10 \%$ in the analyzed region. The complete elimination of water content from both fully saturated samples to their dry state causes an increase of about $80 \%$ and $90 \%$ of their soil reflectance in the spectral region of $1450 \mathrm{~nm}$ and $1950 \mathrm{~nm}$, respectively. Excluding these spectral regions, this increase does not exceed $50 \%$ and $80 \%$ in the near infrared and short infrared spectral regions, respectively. The soil reflectance measured under field conditions in comparison to the reflectance collected under laboratory conditions is lower of about $20 \%$ in the range from 400 $\mathrm{nm}$ to $700 \mathrm{~nm}$.

\section{Acknowledgments}

The work was supported by the Polish Ministry of Science and Higher Education within the framework of the project No. NN 306013637. The authors would like to thank mgr Przemysław Siuchniński for his help in collecting the soil samples and their analysis in the laboratory.

\section{References}

Bednarek R., CharzyńsKi P. \& KabAŁa C., 2009. World Reference Base for soil resources 2006. First update 2007 (in Polish). Wydawnictwo Naukowe Universytetu Mikołaja Kopernika, Torun.

BIAŁOUSZ S., 1978. Zastosowanie fotointerpretacji do wykonywania map stosunków wodnych gleb. PTG, Prace Komisji Naukowych 35: 1-143.

BOWERS S.A. \& HANKS R.J., 1965. Reflection of radiant energy from soils. Soil Science 100, 130-138.

BOWERS S.A. \& SMITH S.J., 1972. Spectrophotometric determination of soil water content. Soil Science Society of America Proceedings 36, 978-980.

CierniewsKi J., 1985. Relation between soil moisture tension and spectra reflectance of different soils in the visible and near-infrared range. Proceeding $3^{\text {rd }}$ International Colloquium on Spectral Signatures of Objects in Remote Sensing, ESA SP-24: 429-432.

CierniewsKi J., 1987. A model for soil surface roughness influence on the spectral response of bare soils in the visible and near-infrared range. Remote Sensing of Environment, 23, 97-115.

Cierniewski J., 1993. Soil moisture tension and soil spectral reflectance on the example of the Kościan Plain soils. Fotointerpretacja w Geografii 23: 107-123.
Clark R.N., 1999. Spectroscopy of Rocks and Minerals and Principles of Spectroscopy. In: A.N. Rencz (ed.), Manual of Remote Sensing. John Wiley and Sons, New York: 3-58.

ConDIT H.R., 1970. The spectral reflectance of American soils. Photogrammetric Engineering \& Remote Sensing 36: 955-966.

Coulson K.L. \& ReYNOLDS D.W., 1971. The spectral reflectance of natural surfaces. Journal of Applied Meteorology 10: 1285-1295.

Cozzolino D. \& Moron A., 2003. The potential of nearinfrared reflectance spectroscopy to analyse soil chemical and physical characteristics. Journal of Agricultural Sciences 140: 65-71.

Curran P.J., Foody G.M., Kondratyev K.Ya., Kozoderov V.V. \& FEDChENKO P.P., 1990. Remote sensing of soils and vegetation in the USSR. Taylor \& Francis, London, New York, Philadelphia.

DALAL R.C. \& HenRY R.J., 1986. Simultaneous determination of moisture, organic carbon and total nitrogen by near infrared reflectance spectrophotometry. Soil Science Society of America Journal 50: 120-123.

DotKov I.S. \& VinOGRAdOVA G.B., 1973. Koefficient otrazeniya vlaznych pochv. Pochvovedenije 11: 114-123.

Islam K., Singh B. \& McBratney A.B., 2003. Simultaneous estimation of various soil properties by ultra-violet, visible and near-infrared reflectance spectroscopy. Australian Journal of Soil Research 41: 1101- 1114.

Lagacherie P., Frédéric B., Feret J.-B., Netto J.M. \& RobBEZ-MASSON J.M., 2008. Estimation of soil clay and calcium carbonate using laboratory, field and airborne hyperspectral measurements. Remote Sensing of Environment 112: 825-835.

McCarty G.W., Reeves III J.B., Reeves V.B., Follett R.F. \& KimBLE J.M., 2002. Mid-infrared and near-infrared diffuse reflectance spectroscopy for soil carbon measurements. Soil Science Society of America Journal 66: 640- 646.

Mikhaylova N.A. \& OrLOv D.S., 1986. Opticheskiye svoystva pochv i pochvennykh komponentov. Nauka, Moskva.

Mulders M.A., 1987. Remote Sensing in Soil Science. 15, Elsevier, Amsterdam, Oxford, New York, Tokyo.

Music H.B. \& Pelletier R.E., 1986. Response of some Thematic Mapper band rations to variation in soil water content. Photogrammetric Engineering and Remote Sensing 52: 1661-1668.

Oвuкhov A.I. \& ORLov D.S., 1964. Spectral reflectivity of the major soil groups and possibility of using diffuse reflection (in Russian). Pochvovedenije 28: 83-94.

ORLOV D.S., 1969. Quantitative laws of reflection of light by soil. IV. Varying indices and the effect of humus substances (in Russian). Nauchnye Doklady Vysshey Shkoly. Biologicheskiye Nauki 8: 131-134.

Orlov D.S., BiLdebaeva R.M. \& SAdOvnikov Yu.N., 1976. Kaličestvennye zakony otraženija sveta ot počvy. Vlijanie razmera časti na otraženije (in Russian). Nauchnye Doklady Vysshey Shkoly. Biologicheskiye Nauki 20: 109-113.

Piech K.R. \& WALKer J.E., 1974. Interpretation of soils. Photogrammetric Engineering 40: 87-94. 
Reginato R.J., VedDeR J.F., IDSO S.B., JACKSON R.D., Blanchard M.B. \& GotTelman R., 1977. An evaluation of total solar reflectance and spectral band ratioing techniques for estimating soil water content. Journal of Geophysical Research 82: 2100-2104.

Scheinost A.C., Chavernas A., Barrón V. \& Torrent J., 1998. Use and limitations of second derivative diffuse reflectance spectroscopy in the visible to near-infrared range to identify and quantify Fe oxide minerals in soils. Clay Minerals 45: 528-536.

SpARKs D.L. (ed.), 1996. Methods of Soil Analysis. Part 3. Chemical methods, Soil Science Society of America and American Society of Agronomy, Madison.

StONER E.R. \& BAUMGARDNER M.F., 1981. Characteristic variations in reflectance of surface soils. Soil Science Society of
American Journal 45: 1161-1165.

VinOGRAdOv B.V., 1983. Kolichestvennoye vyrazenie funkcii distancionnoj indikacii vlaznostii pochv. Doklady Akademii Nauk SSR 272: 247-250.

TOlCHELNIKOV I.S., 1974. Opticheskiye svoystva landschafta. Nauka, Leningrad.

VAN Waes C., 2005. Possibilities of near infrared reflectance spectroscopy for the prediction of organic carbon concentrations in grassland soils. Journal of Agricultural Science 143: 487-492.

VISCARRA-Rossel R., 2008. The Soil Spectroscopy Group and the development of a global spectral library. IUSS Bulletin 113: 30-32. 